\title{
Atenção à primeira infância finlandesa e brasileira: alternativas de atendimento, atendimentos alternativos
}

\author{
Tatiane Oliveira Zanfelici
}

\begin{abstract}
Resumo
Os estudos da OCDE acerca dos benefícios e direitos universais a uma educação infantil de qualidade vêm suscitando discussões sobre os padrões desta modalidade de educação em diversos países. Diante disso, a Finlândia, entre outros países escandinavos, destaca-se por manter há anos políticas de favorecimento às famílias e crianças que consistem numa ação coerente de unificação das forças do Estado e das famílias. O Brasil tem se utilizado de alguns destes programas estrangeiros para atender de forma adaptada aos excluídos das oportunidades de educação. A partir de documentos do Ministério das Relações Sociais finlandês, do Ministério da Educação brasileiro, de dados estatísticos e literatura científica, o objetivo deste artigo foi descrever, comparar e discutir dois sistemas alternativos de educação similares nos dois países. Ressalta-se a importância da ampliação das discussões e pesquisas na área a fim de obter um panorama sobre as vantagens ou desvantagens da manutenção destes programas.
\end{abstract}

Palavras-chave: Educação infantil, educação não-formal, política governamental.

\section{Brazilian and Finnish early childhood care: options of care, alternative care}

\begin{abstract}
The OECD studies about the benefits and universal rights to a quality early childhood education have promoted discussions about raising the standards of this mode of education in various countries. Thus, Finland, among other Scandinavian countries, stands out for maintaining for years of political favoritism to families and children. This is a consistent action to unify the forces of the state and families. Brazil has been using some of these foreign programs in order to help the excluded from the opportunities of education. The purpose of this work is to describe , compare and discuss two systems of alternative education similar in the two countries, based on the documents from the Finnish Ministry of Social Affairs and Health, the Brazilian Ministry of Education, statistical data and scientific literature. We emphasize the importance of broadening the discussions and studies in the area in order to get an overview of the advantages or disadvantages of maintaining these programs.
\end{abstract}

Keywords: Early childhood education, non-formal education, government policy making.

\section{Atención a la primera infancia finlandesa y brasileña: alternativas de atendimiento, atendimientos alternativos}

\begin{abstract}
Resumen
Los estudios de la OCDE al respecto de los beneficios y derechos universales a una educación infantil de calidad están suscitando discusiones sobre los modelos de este tipo de educación en diversos países. Frente a esto, Finlandia, entre otros países escandinavos, se destaca por mantener hace años políticas de beneficio a familias y niños que consisten en una acción coherente de unificar las fuerzas del Estado y de las familias. Brasil ha utilizado de forma adaptada algunos de estos programas extranjeros para atender a los excluidos de las oportunidades de educación. A partir de documentos del Ministerio de Relaciones Sociales finlandés, del Ministerio de la Educación brasileño, de datos estadísticos y literatura científica, el objetivo de este artículo fue describir, comparar y discutir dos sistemas alternativos de educación similares en los dos países. Se resalta la importancia de la ampliación de las discusiones e investigaciones en el área con la finalidad de obtener un panorama sobre las ventajas o desventajas del mantenimiento de estos programas.
\end{abstract}

Palabras-clave: Educación infantil, educación no formal, políticas gubernamentales. 


\section{Introdução}

Desde a década de 1990, os países membros da Organização para a Cooperação e Desenvolvimento Econômico (OCDE) demonstram uma intensa preocupação em investigar a importância de educação e cuidado adequados na primeira infância e suas consequências ao longo da vida do indivíduo. As questões sobre o assunto foram suscitadas, entre outros fatores, a partir de dados científicos e socioeconômicos que comprovavam melhores resultados no desenvolvimento cognitivo, acadêmico, social e emocional das crianças que tiveram acesso a experiências precoces e de qualidade nos primeiros anos de vida (UNESCO, 2002). Discussões posteriores apontaram que os serviços de educação e cuidado infantil funcionariam como fator atenuante de condições desfavoráveis de vida, como a pobreza; preveniriam ou detectariam precocemente situações como as de fracasso escolar; e ainda serviriam como um recurso de inclusão social, à medida que proporcionassem oportunidades iguais de acesso aos mesmos serviços, sem priorizar minorias (UNESCO, 2002).

$\mathrm{Na}$ maioria dos países membros da OCDE, os objetivos que fundamentam as políticas de educação e cuidado infantil são: fornecer apoio e condições de igualdade de oportunidades a crianças em situação de risco e seus familiares, possibilitando a integração social, colaborar na implantação de instituições que favoreçam o desenvolvimento e bem-estar para as crianças, facilitar a transição para o ensino fundamental e favorecer o trabalho das mães de crianças pequenas, bem como sua conciliação com a vida familiar (UNESCO, 2002). Segundo Freitas e Shelton (2005), em termos de economia, já foi sugerido que os programas destinados à primeira infância sejam encarados por cidadãos e governantes como investimento e não como despesa, tendo em vista os imensos benefícios que tais programas podem proporcionar. Todavia, de acordo com Choi (2002a), os governos de países de ideologias tradicionalmente orientadas para o mercado, como os Estados Unidos, Reino Unido e Austrália, ainda tendem a envolver-se minimamente com as políticas de proteção às crianças pequenas e suas famílias, ao contrário dos países nórdicos (Dinamarca, Finlândia, Noruega e Suécia), pioneiros na criação de tais políticas. Haddad (2006) argumenta que o maior envolvimento dos países escandinavos nas políticas familiares pode ter acontecido como consequência das novas tendências em educação que emergiram nos anos sessenta e trouxeram aos mesmos países mudanças bastante significativas nos conceitos de cuidado e socialização infantil, bem como grandes investimentos públicos nesta área.

Assim como acontece em outros países da América Latina, no Brasil, a educação infantil caracteriza-se como uma área ainda em desenvolvimento, que necessita de maior valorização, investimentos e ampliação dos serviços. Apesar de ter sido reconhecida no país como "direito da criança, opção da família e dever do Estado" (MEC, 2006, p.5) e incorporada, desde 1996, à educação básica, a educação infantil ainda deixa a desejar, não contemplando toda a população que a requer. Na prática, não é respeitado o direito da criança, nem é oferecida a opção aos pais, já que nem todos têm acesso a este serviço. O Estado, por sua vez, tem procurado sanar as imensas filas de espera por vagas em serviços formais de educação infantil com programas alternativos, semelhantes a bem-sucedidos modelos de atendimento à primeira infância em países desenvolvidos, porém muitas vezes pobremente adaptados e de qualidade duvidosa.

Dois exemplos de programas substitutivos à educação formal e comumente utilizados em diversas regiões do Brasil são o sistema de creches domiciliares (ou mãe-crecheira) e a bolsa-creche. Tais serviços também são comuns na Finlândia já há alguns anos, porém uma das diferenças fundamentais em relação ao Brasil é o caráter realmente alternativo (e não substitutivo) dos programas finlandeses, que podem ser escolhidos pelos pais conforme suas necessidades. Esta diferença, entre outras tantas quando comparados serviços aparentemente semelhantes nos dois países, suscitaram o objetivo deste artigo: descrever, comparar e discutir os serviços de educação e cuidado público e privado, formal e domiciliar; no Brasil e na Finlândia. Para tanto, examinaram-se documentos oficiais de ambos os países que contemplavam as informações de interesse para esta discussão. No caso da Finlândia, esses documentos estão disponíveis na Internet no idioma inglês, concentrados nas páginas do Ministério das Relações Sociais e Saúde (Ministry of Social Affairs and Health) local. Os documentos brasileiros consultados, também acessíveis pela Internet, foram elaborados pelo Ministério de Educação e Cultura (MEC), pelo Instituto Nacional de Ensino e Pesquisa (INEP) e pelo Instituto Brasileiro de Geografia e Estatística (IBGE).

\section{Políticas familiares finlandesas: um passo à frente no atendimento às crianças pequenas}

Apesar de não ter sido o primeiro país nórdico a investir em políticas de bem-estar familiar, desde 1948, a Finlândia já demonstrava os primeiros indícios de preocupação na área, instituindo um sistema de subsídios para crianças que, por muitos anos, foi uma maneira de contribuir na melhoria da renda dos cidadãos com filhos pequenos (Finland, 2006b). Atualmente, este é um dos países com maior coerência na unificação de forças do Estado e da família comprometidas com o desenvolvimento integral da criança. Fundamentadas nos princípios de bem-estar social, as políticas familiares (family policy) finlandesas visam garantir condições materiais e psicológicas para que as famílias possam equilibrar suas demandas entre trabalho pago e familiar, especialmente em situações em que a presença das pessoas é mais exigida, como nos primeiros anos de vida da criança ou quando existem familiares com alto nível de dependência funcional.

Além de colaborar na administração de problemas frequentemente enfrentados pelos trabalhadores e suas famílias - como o estresse profissional e a dificuldade de conciliação de horários - e na divisão equitativa dos cuidados com os filhos, as políticas familiares apresentam diversas alternativas de cuidado e educação que contribuem 
substancialmente com as condições necessárias para um adequado desenvolvimento infantil (Finland, 2006a). Outro mérito das políticas familiares é a possibilidade de colaborar com a manutenção do emprego das finlandesas, que, devido a fatores históricos, sempre estiveram comprometidas com o trabalho pago externo aos lares. Evita-se assim que muitas mães evadam dos seus empregos para se dedicarem exclusivamente ao cuidado com os filhos. Choi (2002b) argumenta que tais políticas consequentemente favorecem também os filhos de mães que não trabalham, suprindo um espaço necessário à educação e estimulação das crianças que nem sempre é explorado adequadamente, e diminuindo a sobrecarga de trabalho das mães donas de casa.

\section{Os serviços de atenção à primeira infância na Finlândia}

Segundo o Ministério das Relações Sociais e da Saúde (Finland, 2004), após o período de licença parental, que na Finlândia dura nove meses e pode ser dividida entre pai e mãe, a lei do país impõe que os governos municipais responsabilizem-se por garantir às crianças pré-escolares (usualmente até os sete anos) uma vaga nos serviços de assistência diurna. Para as famílias, o serviço é opcional, podendo ser dispensado nos casos em que um dos pais preferira afastar-se temporariamente do emprego para se dedicar aos cuidados com o filho. Três das alternativas de serviços para pré-escolares disponíveis aos finlandeses são: 1) centros municipais de cuidado e educação infantil (daycare), 2) educação individual ou grupal, supervisionada por profissional (family daycare), 3) serviços privados de cuidado e educação infantil financiados parcialmente pelo governo (private child care allowance).

Os serviços de daycare finlandeses visam combinar ensino e cuidado aos alunos pré-escolares, desde o término da licença parental até o momento em que a criança completa sete anos e deve ser encaminhada para a escolarização obrigatória. Este modelo, também conhecido como educare, não é comum em todos os países da Europa e emergiu na Finlândia devido às necessidades apresentadas pelos filhos de pais que trabalham o dia todo (Finland, 2006b). Em vigor desde 1996, este atendimento tem sido o preferido entre as demais alternativas de educação e cuidado infantil nas famílias de crianças entre três e sete anos de idade $-32,4 \%$ de tais famílias utilizaram o serviço em 2005 (Finland, 2006c).

Todas as crianças abaixo da idade escolar têm direito a este serviço. Para tanto, não é necessário que os pais da criança estejam empregados, estendendo assim este benefício a filhos de pessoas que não trabalham de forma remunerada (por exemplo, donas de casa). A renda familiar das crianças também não fundamenta critérios de inclusão para a conquista de vagas nos centros de educação e cuidado infantil, porém as famílias usuárias contribuem mensalmente com o serviço com quantias que variam de acordo com sua faixa salarial e as de baixa renda são totalmente isentas de custos. Tais contribuições são responsáveis pelo suprimento de aproximadamente $15 \%$ dos gastos do Estado com as daycare. De acordo com a tabela de valores vigente até o ano de 2006, o valor desta mensalidade nunca ultrapassava o teto de 200 euros para o primeiro filho, 180 euros para o segundo filho e 40 euros para cada criança subsequente (Finland, 2006c). No ano de 2005, as despesas com benefícios para famílias com crianças totalizaram aproximadamente 5,2 bilhões de euros, isto é, $3 \%$ do GDP ${ }^{1}$ do país, sendo que $27,2 \%$ deste valor foi gasto com os serviços de daycare (Finland, 2006b).

Cerca de $77 \%$ das crianças usuárias dos serviços de daycare frequentam as instituições em período integral (Finland, 2006b). Neste caso, a razão entre profissionais (professores ou cuidadores) e alunos é de 1:4 - em grupos de crianças abaixo da idade de três anos -, e 1:7 em grupos de faixa etária entre três a seis anos. Na modalidade de atendimento em tempo parcial, as crianças menores de três anos contam com a mesma proporção entre adultos e crianças frequentadoras do atendimento integral, porém as crianças maiores são organizadas em grupos de treze para cada profissional. Os profissionais das daycare necessitam ter pelo menos o segundo grau completo, obrigatoriamente. Além disso, é exigido que um em cada três destes profissionais tenham também o nível superior de ensino, como o bacharelado ou mestrado em Educação ou o bacharelado em Ciências Sociais (Finland, 2004).

Além das modalidades de cuidado integral e parcial, os governos municipais também provêem instituições que trabalham 24 horas para atender aos pais de crianças que trabalham em turnos (Finland, 2006a). Como existem cidades finlandesas que são bilíngues, o município deve assegurar também que seus centros de educação e cuidado infantil ofereçam atendimentos no idioma que a mãe da criança fala, em uma das linguagens oficiais da Finlândia (finlandês ou sueco), e as instituições de daycare municipais têm o dever de garantir o suporte necessário para que sejam respeitados na educação e no cuidado às crianças imigrantes seus idiomas e culturas natais (Finland, 2004). O ensino é baseado no currículo escolar local que, por sua vez, é derivado do currículo escolar nacional e sua carga horária deve oferecer pelo menos 700 horas de educação no decorrer do ano letivo, em todos os municípios (três a quatro horas diárias) (Finland, 2006b).

Um outro arranjo de daycare é o family daycare, o cuidado infantil supervisionado por um cuidador (ou cuidadora) de crianças, o child minder's. Este profissional necessita ser formado em treinamento apropriado, preferivelmente tendo sido concluído o curso de qualificação vocacional adequado para tais objetivos. Tal tipo de cuidado pode ocorrer de forma individual ou em grupos de até quatro crianças, nas próprias casas da família, na casa do cuidador ou então em espaços abertos ao contato com outras crianças, como nos playgrounds (Finland, 2006b). O serviço pode ocorrer em tempo parcial, quando a criança frequentar uma daycare no período oposto, ou então em tempo integral. Neste último caso, a criança não frequentará

1 Gross Domestic Product-correspondente ao que denominamos no Brasil "Produto Interno Bruto" (PIB). 
nenhuma daycare, mas, em contrapartida, os pais optantes pelo serviço integral poderão requisitar ao governo um subsídio para colaborar nas despesas com o cuidador. O valor unitário do subsídio, até dezembro de 2006, era de 137,33 euros mensais, pagos pelo Instituto do Seguro Social diretamente ao cuidador, todavia algumas pessoas recebem ainda benefícios suplementares de até 134,55 euros para colaborar nas despesas, dependendo do tamanho e renda da família (Finland, 2006a). Até o final de 2005, este serviço foi o preferido por $11,1 \%$ dos pais de crianças menores de três anos de idade e $13,4 \%$ dos pais de crianças entre três e sete anos (Finland, 2006b).

Quando os pais das crianças menores de sete anos preferirem que a educação e os cuidados dos filhos sejam proporcionados por instituições privadas, as autoridades municipais finlandesas podem conceder um auxílio financeiro que contribui com as despesas geradas por esta opção de atendimento. Este benefício pode ser recebido desde o final da licença parental até o momento em que a criança completa sete anos, porém é interrompido se a criança for transferida para um centro de educação e cuidado infantil municipal. Até o ano de 2006, o valor mensal do subsídio correspondia a 137,33 euros mensais por criança, valor idêntico ao concedido aos pais que contratam um cuidador particular, sendo que o valor suplementar máximo de 134,55 euros também pode ser ocasionalmente oferecido às famílias (Finland, 2006b). Disponível desde 1997, este benefício é a alternativa menos requerida pelos cidadãos finlandeses. De acordo com estatísticas do ano de 2005, apenas cerca de $2,4 \%$ dos pais de crianças menores de 3 anos de idade utilizaram o subsídio para a contratação de serviços de instituições privadas. Dentre os pais de crianças entre três e sete anos de idade, a procura pelo benefício ficou em torno de $3,8 \%$ (Finland, 2006b). Uma explicação para a escassa procura pelo benefício é o baixo número de instituições de educação e cuidado infantil privadas existentes no país, já que, até 2004 , mais de $90 \%$ dos serviços de daycare eram sustentados pelos municípios (Finland, 2004). A porcentagem de verbas despendidas com este tipo de benefício é também uma das menores entre as destinadas à educação e cuidado infantil, constituindo somente $1 \%$ do total das despesas do governo com políticas familiares (Finland, 2006c).

A despeito do caráter voluntário da educação infantil finlandesa, um levantamento feito no ano de 2006 com crianças de seis anos de idade apontou que 95\% destas crianças frequentavam os serviços de daycare (Finland, 2006b).

\section{Os números nos serviços de atenção à primeira infância no Brasil}

De acordo com o Instituto Brasileiro de Geografia e Estatística - IBGE (2006), 40\% das 21.365 .869 crianças na faixa etária de zero a seis anos de idade frequentavam uma creche ou pré-escola até o ano de 2005. Esses números são ainda menores quando restritos à faixa de zero a três anos de idade, da qual apenas $13 \%$ das 11.496 .926 crianças brasileiras frequentava creche. O censo educacional do Instituto Nacional de Ensino e Pesquisa (2006) apontou um aumento de $1 \%$ no número total de matrículas em creches em relação a 2005, porém os estados do Acre, Pará, Amapá, Tocantins, Sergipe e São Paulo registraram diminuições significativas no número de matrículas neste mesmo período, as quais chegaram a uma redução de $-9,97 \%$.

Mesmo consistindo numa modalidade de educação opcional, até o momento, a creche brasileira tem mantido um importante espaço de proteção e assistência a muitas crianças, inclusive àquelas em situação de risco. Porém, além da insuficiência de vagas para atender à demanda, muitas creches brasileiras, especialmente as que atendem camadas mais baixas, enfrentam ainda uma grande carência de recursos que vai desde a falta de profissionais especializados até a ausência de instalações básicas, como um berçário ou um parque de diversões adequado. Espaços físicos e mobiliários importantes para o cuidado infantil ainda não estão disponíveis em todas as instituições. Exemplos são a enfermaria, presente em menos de $10 \%$ das creches do país; o fraldário, que só constava em 23,5\% destas; e a cadeira específica para alimentar bebês (cadeirão), encontrada em $25,2 \%$ das instituições participantes do último censo da educação infantil (INEP, 2000).

Embora a maioria dos serviços de atendimento à primeira infância seja mantida basicamente pela rede municipal de ensino, o sistema privado ainda é responsável por um alto número de instituições de educação infantil, constituindo $35,8 \%$ do total das creches e $25,77 \%$ das préescolas do país (INEP, 2006). O alto índice de instituições privadas, somado à baixa quantidade de serviços públicos na área, possibilita auxílio na compreensão de alguns dados sobre a situação econômica atual das crianças incluídas e excluídas no sistema de educação infantil.

Segundo o IBGE (2007), somente $15,5 \%$ das crianças de zero a três anos, cuja renda familiar per capita não ultrapassava meio salário mínimo na época da pesquisa, frequentavam uma creche. Este número elevava-se a 40,7\% somente nos casos em que a mesma renda era superior a três salários mínimos. Quando a questão é a etnia declarada pelos participantes do censo educacional, a quantidade de alunos que se declaram brancos ou pardos prevalece desde a educação infantil, já que, segundo o INEP (2006), $39,6 \%$ desses alunos se declararam brancos e $30,71 \%$ se declararam pardos. Não declararam sua cor ou raça 17,98\% dos alunos entrevistados na ocasião e apenas a menor parte declarou-se negra, amarela ou indígena, totalizando 119.048 alunos dos 1.427.942 respondentes (INEP, 2006). Assim, desde os primeiros anos escolares, o sistema público configura uma situação de exclusão social, em que são favorecidos grupos étnicos e socioeconômicos. A educação infantil não é garantida como direito, nem cumpre sua meta de inclusão social, já que definitivamente não está ao alcance de todos aqueles que a requerem. 


\section{O programa Bolsa-Creche e o sistema de creches domiciliares como educação substitutiva}

Diante dos números que representam o perfil das crianças excluídas do sistema educacional infantil, podese afirmar que, apesar de ter ganhado espaço junto aos trabalhadores e suas famílias em diversas regiões do país ao longo dos anos, a creche pública ainda não pode ser considerada o ambiente dominante ou preferido na educação e cuidado da primeira infância. Para preencher as lacunas produzidas pelo curto alcance dos serviços de educação infantil, o Brasil tem se servido de programas informais mantidos por agências governamentais, grupos comunitários, fundações e instituições privadas agindo em conjunto ou isoladamente. Atualmente, o programa bolsa-creche e o sistema de creches domiciliares talvez sejam as alternativas mais comumente financiadas pelos municípios quando a procura por educação infantil torna-se demasiadamente superior à oferta.

O programa Bolsa-Creche é um subsídio concedido por alguns municípios para pagamento parcial ou total de creches particulares quando há de filas de espera no sistema público. Para participar do programa, as instituições interessadas necessitam de um cadastramento, no qual os principais critérios para que sejam admitidas é o valor da mensalidade (que não deve ultrapassar o valor oferecido pelo subsídio quando este oferece cobertura total da mensalidade) e a exatidão da documentação necessária para funcionamento do estabelecimento de ensino (por exemplo, alvará de funcionamento expedido após parecer da secretaria da educação, com autorização para atuação na educação infantil, plano gestor e adendos, matriz curricular e calendário escolar homologados pela secretaria da educação). Embora compreensíveis, tais exigências desencadeiam barreiras que dificultam a adesão de diversas instituições ao programa, já que comumente aquelas que atendem os requisitos burocráticos não mantêm mensalidades dentro do teto fixado. Além dos problemas já conhecidos de falta de verba suficiente para atender a toda a demanda, impõem-se ainda mais barreiras às crianças menos favorecidas, marginalizando o direito do acesso à educação e dificultando a opção por este tipo de serviço.

Outro serviço comum em países como a Finlândia, porém bastante questionado na cultura brasileira, é o sistema de creches domiciliares ou mãe-crecheira. Segundo Bento e Meneghel (2003), tais serviços surgiram no Brasil ao final da década de 70 , visando sanar provisoriamente as necessidades de crianças em situação socioeconômica precária que não encontravam vagas na rede oficial de ensino. Quase três décadas depois, as creches domiciliares ainda são comuns em diversos municípios onde as vagas no sistema público de educação infantil são insuficientes para atender à demanda. Estes programas são autorizados pelos governos municipais, que pagam quantias de até $R \$ 70,00$ a mães que se habilitem a cuidar de grupos de até oito crianças que morem nos arredores e tenham entre seis meses e seis anos de idade. Os alimentos, o botijão de gás e os produtos de limpeza utilizados com as crianças podem ser fornecidos pelo governo ou doados pela vizinhança. Ao contrário do que se possa pensar, essa modalidade de atendimento não está presente apenas em regiões relativamente pobres, mas tem sido recorrente também em diversas cidades do Sul e Sudeste brasileiro.

Rossetti-Ferreira, Ramon e Silva (2002) argumentam que este sistema não responde de maneira adequada às necessidades de educação e cuidado infantil em nosso país porque os índices de educação da população são predominantemente baixos e há pouco investimento em remuneração e formação de pessoal, caracterizando o que as autoras chamam de "atender pobremente a pobreza", incentivando a exploração da mão de obra feminina e o cuidado não profissionalizado. Além da visível diferença entre a formação dos cuidadores e das condições disponíveis no sistema de creche domiciliar nos dois países, é importante lembrar que, no Brasil, este sistema - tal como o BolsaCreche - é uma maneira paliativa de proporcionar educação e cuidado às crianças que não conseguem obtê-los formalmente. Portanto, ao contrário do que muitos insistem, não pode ser denominado alternativa, já que não é possível escolher uma forma mais conveniente de educar entre outras opções, como acontece na Finlândia. Para ilustrar esta reflexão, é válida a questão anteriormente levantada por Rossetti-Ferreira e cols. (2002): embora os programas substitutivos ofereçam uma alternativa às famílias que não encontram vaga no sistema de educação infantil formal, as famílias usuárias optariam por tais serviços em detrimento daqueles oferecidos por creches e pré-escolas?

\section{Considerações Finais}

As discussões propostas nos últimos anos a partir do estudo realizado pela UNESCO/OCDE (2002) trazem em comum a preocupação com a garantia do direito da criança a uma educação que contribua para os objetivos de proteção em situação de risco, que estimule o desenvolvimento integral das crianças e que facilite a transição para a educação obrigatória. Contudo, mesmo diante dos sólidos fundamentos apresentados pelos estudos da UNESCO como justificativa à importância da educação infantil no desenvolvimento integral e bem-estar das crianças, o relatório anual Education for All Global Monitoring Reports (UNESCO, 2006) destaca que a América Latina e o Caribe ainda têm muito a fazer para alcançar níveis ótimos de atendimento a esta clientela. $O$ mesmo relatório aponta também que a metade dos países do mundo ainda não possui políticas de proteção nem leis educacionais que favoreçam a primeira infância.

Embora já existam leis e documentos brasileiros que tratam sobre os princípios, metas e estratégias para uma educação infantil de qualidade, a literatura acerca das formas alternativas de educação e cuidado infantil, tão comuns em nosso país, ainda á incipiente. É importante que sejam incentivadas mais pesquisas baseadas em estatísticas e experiências com educação informal e que a sociedade 
seja levada a discutir e refletir sobre estas alternativas, que podem ser compreendidas como avanço ou retrocesso social. Programas de baixo custo e qualidade questionável desconsideram prejuízos posteriores, que frequentemente desencadeiam transtornos aos indivíduos e provavelmente levarão a segundas despesas.

O Brasil tem lutado nas últimas décadas para alcançar melhorias e abrangência populacional na educação infantil formal mesmo que, talvez por ser optativa, esta ainda não seja vista como prioritária por muitos. Contudo, para que possam ser assegurados seus objetivos de proteção, estimulação e inclusão, a educação infantil parece necessitar de fundamentos políticos menos assistencialistas e mais emancipatórios que visem consolidar esta modalidade educacional como um direito universal e não como uma benesse concedida pelos governos aos cidadãos mais carentes.

Este estudo comparou serviços e políticas de dois países bastante diferenciados em termos demográficos, socioculturais e históricos. Assim, o atendimento finlandês não deve ser compreendido como modelo ou meta a ser alcançada pelos programas brasileiros. Pretendeuse proporcionar uma reflexão a partir de formas bastante diferenciadas de organização e entendimento acerca da educação infantil, apresentando-se, para tanto, um conjunto de políticas bastante consolidado e bem-sucedido em seu país de origem, os quais podem trazer indícios para ações que colaborem para reformulações nas políticas educacionais e atendam às necessidades de nossas crianças e sociedade.

\section{Referências}

Bento, K. L., \& Meneghel, S. M. (2003). As Creches Domiciliares como Espaços de Educação Infantil. Trabalho apresentado na 26a Reunião Anual da ANPED: Poços de Caldas, MG.

Choi, S. (2002a). Women, Work and Early Childhood: The Nexus Developed and Developing Countries (I). UNESCO Policy Brief on Early Childhood, 4 (June). Paris: UNESCO.
Choi, S. (2002b). Women, Work and Early Childhood: The Nexus Developed and Developing Countries (II). UNESCO Policy Brief on Early Childhood, 5 (July - August). Paris: UNESCO.

Finland. (2004). Early Child Education and Care in Finland (3a ed). Helsinki, Finland: Suomen Printman,.

Finland. (2006a). Child Care Subsidies. Helsinki, Finland. Recuperado: 12 jul 2007. Disponível: www.stm.fi/english.

Finland. (2006b). Finland's Family Policy. Helsinki, Finland: University Printing House.

Finland (2006c). Social Welfare in Finland. Helsinki, Finland: University Printing House.

Freitas, L. B. L., \& Shelton, T. L. (2005). Atenção à Primeira Infância nos EUA e no Brasil. Psicologia Teoria e Pesquisa, 21(2), 197205.

Haddad, L. (2006). Políticas Integradas de Educação e Cuidado Infantil: Desafios, Armadilhas e Possibilidades. Cadernos de Pesquisa, 36(129), 519-546.

Instituto Brasileiro de Geografia e Estatística - IBGE. (2007). Síntese de Indicadores Sociais: Uma análise das condições de vida da população brasileira. Estudos e Pesquisas, 21.

Instituto Nacional de Ensino e Pesquisa - INEP. (2000). Censo da Educação Infantil. Recuperado: 06 ago 2007. Disponível: www. inep.gov.br.

Instituto Nacional de Ensino e Pesquisa - INEP. (2006). Censo Escolar da Educação Básica 2006. Recuperado: 06 ago 2007. Disponível: www.inep.gov.br.

Ministério da Educação e do Desporto. Secretaria de Educação Básica. (2006). Política Nacional de Educação Infantil: Pelo Direito das Crianças de 0 a 6 Anos à Educação. Brasília: MEC/ SEB.

Rossetti-Ferreira, M. C., Ramon, F., \& Silva, A. P. S. (2002). Políticas de Atendimento à Criança Pequena nos Países em Desenvolvimento. Cadernos de Pesquisa, 115, 65-100.

UNESCO - Organização das Nações Unidas para a Educação, a Ciência e a Cultura. (2002). Educação e Cuidado na Primeira Infância: Grandes Desafios. Brasília: UNESCO Brasil.

UNESCO - Organização das Nações Unidas para a Educação, a Ciência e a Cultura. (2006). Education for All Global Monitoring Reports. Paris: UNESCO.
Recebido em: 30/10/2008

Reformulado em: 13/01/2010 Aprovado em: 14/01/2010

\section{Sobre a autora}

Tatiane Oliveira Zanfelici (zantatiane@yahoo.com.br)

Universidade Federal de São Carlos, SP.

\section{Correspondência}

Tatiane Oliveira Zanfelici

Rua João Boteon, no. 78, Vila Boteon

Cordeirópolis - SP - CEP 13490-000

Agradecimento

A autora agradece as sugestões concedidas pela professora Dra. Maria Cristina P. I. Hayashi para a elaboração deste artigo. 